\title{
POTENCIAL DE UTILIZAÇÃO MADEIREIRA DE ESPÉCIES FLORESTAIS DE VÁRZEA NO MUNICÍPIO DE MAZAGÃO NO ESTADO DO AMAPÁ
}

\author{
José Antonio Leite de Queiroz*, Sebastião do Amaral Machado** \\ *Eng. Florestal, M.Sc., Doutorando em Engenharia Florestal, UFPR, Embrapa Amapá - leite.queiroz@terra.com.br \\ **Eng. Florestal, PhD., Depto. de Ciências Florestais, UFPR - sammac@floresta.ufpr.br \\ Recebido para publicação: 28/09/2006 - Aceito para publicação: 31/01/2007
}

\begin{abstract}
Resumo
O presente estudo foi desenvolvido objetivando avaliar o potencial de utilização madeireira das espécies de várzea estuarina amazônica, no município de Mazagão, estado do Amapá, e estimar o estoque de madeira das espécies exploradas. Para avaliar o potencial de utilização madeireira, aplicou-se questionário para levantamento de informações socioeconômicas dos proprietários das pequenas serrarias existentes no rio Mazagão, rio Mutuacá e rio Ajudante, tributários do rio Amazonas. Para estimar o estoque de madeira existente das espécies exploradas, foram instaladas cinco parcelas amostrais de 1,0 ha, divididas em subparcelas de $20 \times 50 \mathrm{~m}$. Pelas respostas nos questionários, observou-se que as espécies mais serradas na área são: andiroba (Carapa guianensis Aubl.), pracuúba (Mora paraensis Ducke), pau-mulato (Callycophyllum spruceanum Benth.), macacaúba (Platymiscium filipes Benth.), virola (Virola surinamensis (Rol. Ex Rottb) Wab) e anani (Symphonia globulifera L.). O inventário fitossociológico mostrou que o estoque de madeira das espécies exploradas é satisfatório, com 71,8 árvores/ha com DAP entre 20 e $40 \mathrm{~cm}$ e 28,2 árvores/ha com DAP $>40 \mathrm{~cm}$. Atualmente, em média, em cada serraria são produzidas, por dia, 20 dúzias de tábuas e pernamancas, pelo beneficiamento de 7 a 8 toras de madeira, obtidas com derrubada de duas árvores.

Palavras-chave: Amazônia; estuário; madeira; exploração florestal.
\end{abstract}

\begin{abstract}
Potential of wood utilization of forest species from floodplain in the district of Mazagão in Amapa State. The present study was developed aiming to evaluate the potential of wood utilization of species in Amazon estuarine floodplain, in the district of Mazagão, Amapá State and to estimate the wooden supply of the explored species. To evaluate the potential of wooden utilization, questionnaires were applied for surveying socioeconomic information from small existent sawmills owners in the mazagão river, mutuacá river and ajudante river, tributaries of the Amazon river. Five sample plots of one hectare divided in sub-plots of $20 \times 50 \mathrm{~m}$ were installed, for evaluation of the existent wood stock of the exploited species. From the answers of the questionnaires it was observed that the most sawed species in the area are: andiroba (Carapa guianensis Aubl.), pracuúba (Mora paraensis Ducke), Pau mulato (Callycophyllum spruceanum Benth.), macacaúba (Platymiscium filipes Benth.), Virola (Virola surinamensis (Rol. Ex Rottb) Warb.) and anani (Symphonia globulifera L.). The phytosociology inventory showed that the wood stock of the exploited species is satisfactory, with 71,8 trees/ha with DBH between 20 and $40 \mathrm{~cm}$ and 28,2 trees/ha with $\mathrm{DBH}>40 \mathrm{~cm}$. Currently, on average, in each sawmill are produced, 20 dozens of boards and rafters, per day, the from 7 to $8 \operatorname{logs}$, from the exploitation of two trees.
\end{abstract}

Keywords: Amazonian; Estuary; wood; forest exploitation.

\section{INTRODUÇÃO}

O estado do Amapá, situado no extremo norte do Brasil, possui uma população em torno de 500 mil habitantes, sendo que mais de $80 \%$ vivem na zona urbana. Dos 100 mil que moram na zona rural, mais de $50 \%$ sobrevivem dos recursos da várzea. Além dos amapaenses, os habitantes das ilhas do Pará,

FLORESTA, Curitiba, PR, v. 37, n. 2, mai./ago. 2007. 
formadas por localidades do município de Afuá e de Gurupá, constituem um total populacional de mais de 50 mil pessoas que mantêm relações socioeconômicas com o estado do Amapá (QUEIROZ, 2004).

A floresta de várzea constitui o segundo maior ambiente florestado da região, considerando seestrutura, diversidade e representatividade espacial. Sua área de abrangência e maior concentração ocorrem principalmente em margens de rios de água barrenta, onde, de certo modo, passa a ser regulada pelos regimes de marés. Na medida em que se avalia o comportamento desse ambiente, a partir das áreas estuarinas para o interior do continente, observa-se profunda redução florística, possivelmente ligada às alterações físico-químicas das águas desses rios (AMAPÁ, 2002).

Rios e lagos da hiléia são muitas vezes acompanhados por faixas de terrenos baixos, sujeitos a inundação durante um determinado período de cada ano. Essas terras baixas são chamadas várzeas, e a floresta que as cobre chama-se "mata de várzea", em contraste com a "mata da terra-firme". As terras baixas da zona costeira da hiléia e do grande estuário amazônico são inundadas pela repercussão das marés atlânticas. A "mata" dos lugares mais baixos, diariamente inundados, aproxima-se do igapó, e a dos lugares mais altos, inundados somente pelas marés grandes, assemelha-se à da várzea de outras partes da região (DUCKE; BLACK, 1954).

O regime de inundação, as diferenças no teor de sedimentos na água, a distância do ponto de origem dos sedimentos e das várzeas das margens dos respectivos rios, a intensidade da inundação e a influência da maré e da água do mar determinam desigualdades significativas no revestimento florístico, na formação do solo, nas características físicas e químicas e na potencialidade agropecuária das áreas inundáveis pelos rios de águas barrentas (LIMA; TOURINHO, 1994).

As várzeas são ambientes frágeis, com origem e funcionamento ligados à deposição de sedimentos geologicamente recentes, profundamente influenciados pelos regimes de marés e de águas pluviais. São as chamadas planícies de inundação, planície quaternária, planícies aluviais, etc. A essas mesmas condições deve-se a formação de solos com bons níveis de nutrientes e estoques biológicos ainda precariamente conhecidos. A utilização desse ambiente está centrada no extrativismo vegetal, principalmente açaí (fruto e palmito), seringa, andiroba, madeira e pecuária extensiva (AMAPÁ, 2000).

Como alternativa para a obtenção de renda monetária, a população ribeirinha que permaneceu no ambiente de várzea e não migrou para os centros urbanos desenvolveu pequenas serrarias familiares, cuja produção de madeira é obtida a partir do uso de espécies de ocorrência destacada, como é o caso da andiroba, da pracuúba, da macacaúba, da virola, do anani e do pau-mulato, entre outras, de boa aceitação nos centros urbanos, onde são utilizadas para a construção de casas, colocação de cercas, fabricação de móveis, etc.

Em relação às espécies madeireiras e não-madeireiras que ocorrem no ambiente estuarino, Queiroz (2004), em estudo realizado no braço norte do rio Amazonas, no estado do Amapá, em 10 hectares distribuídos ao longo do grande rio e de seus tributários, encontrou um total de 116 espécies, com destaque para o açaizeiro (Euterpe oleracea Mart.), considerada a espécie mais importante do ponto de vista socioeconômico, e para as madeiráveis andiroba (Carapa guianensis Aubl.), anani (Symphonia globulifera L.), virola (Virola surinamensis Warb.), macacaúba (Platymiscium filipes Benth.), pracuúba (Mora paraensis Ducke) e pau-mulato (Callycophyllum spruceanum Benth.), entre outras.

Todos os estudos e observações socioeconômicos têm mostrado que a renda familiar dos ribeirinhos do estado do Amapá depende completamente das produções florestais e agroflorestais. O que preocupa, entretanto, é que o alargamento das fronteiras dos açaizais vem gerando, como conseqüência, a redução das espécies lenhosas (QUEIROZ; MOCHIUTTI, 2000).

O município de Mazagão possui uma área de 1.318 .960 ha, sendo 38.160 ha ocupados pelo ecossistema de várzea (RABELO et al., 2005). O extrativismo vegetal centrado na exploração de madeira, coleta de frutos de açaí para extração da polpa, coleta de frutos de andiroba para extração do óleo e coleta de frutos de taperebá, principalmente, aliados à pesca, constituem a principal fonte de renda e de alimento do habitante das áreas rurais do município.

A madeira extraída das áreas de várzea estuarina do município de Mazagão há muito vem suprindo as necessidades de madeira dos nativos do município e parte da demanda por madeira exercida pelos moradores de Santana, o segundo maior município do Estado. O beneficiamento primário da madeira é feito pelas inúmeras serrarias, instaladas às margens dos inúmeros rios, tributários de primeira, segunda e terceira ordem do rio Amazonas, montadas e administradas por famílias locais. No rio Mazagão e seus tributários, Ajudante e Mutuacá, é onde se concentra o maior número de serrarias. 
As serrarias instaladas no município de Afuá (PA), município de Breves (PA) e município de Gurupá (PA) são as principais fornecedoras de madeira para as lojas de venda de madeira instaladas no Canal do Jandiá e no Porto das Pedrinhas (Figura 1), em Macapá (AP). As serrarias instaladas na região do Mazagão, Maracá, Jari e Jarilândia fornecem madeira para as lojas instaladas no município de Santana, no local chamado de "Bueiro".

É nos pontos de venda instalados no Canal do Jandiá, no Porto das Pedrinhas e no Bueiro que se consegue encontrar madeira para construir casas na periferia, fazer forma para o concreto das casas de alvenaria do centro da cidade ou dos bairros nobres, madeira para o forro das casas, para os cercados e para a fabricação de móveis e esquadrias em Macapá e em Santana.

O presente estudo foi desenvolvido objetivando avaliar o potencial de utilização madeireira das espécies de várzea estuarina amazônica, no município de Mazagão, estado do Amapá, e estimar o estoque de madeira existente das espécies exploradas.

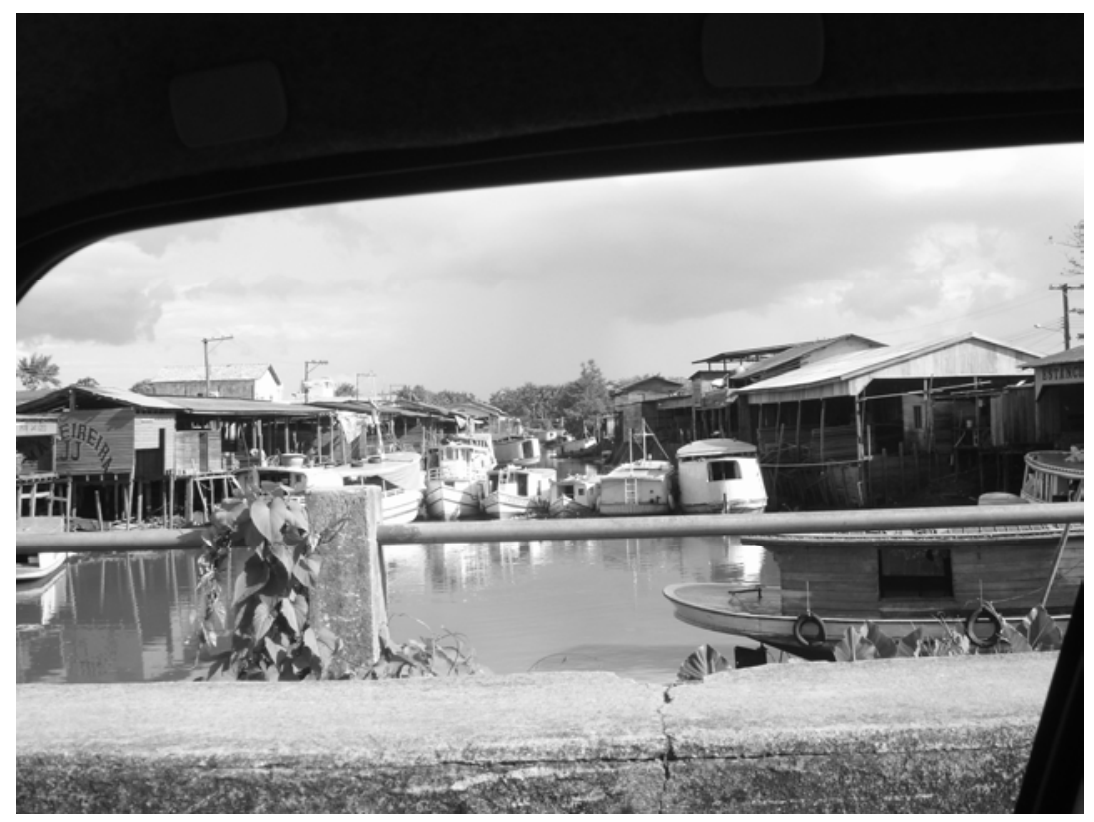

Figura 1. Ponto de compra e venda de madeira no Igarapé das Pedrinhas em Macapá (AP) (Foto do autor). Figure 1. Point of wooden purchase and sale in the "Pedrinhas Igarapé" in Macapá (AP) (Photo of the author).

\section{MATERIAL E MÉTODOS}

Para avaliação do nível atual de utilização das espécies madeireiras locais de várzea, aplicou-se questionário de pesquisa socioeconômica ambiental, e para a avaliação da disponibilidade atual de madeira e estimativa do estoque futuro, realizou-se levantamento fitossociológico em cinco parcelas de um hectare, no município de Mazagão, no estado do Amapá.

A área de estudo representa, aproximadamente, $25 \%$ da área de várzea do município de Mazagão ( \pm 10.000 ha), onde existem 28 serrarias funcionando. Para a pesquisa socioeconômica, aplicouse questionário a proprietários de dez serrarias, com base na exploração anual de madeira no local que, em média, chega a 300 árvores, algo em torno de $500 \mathrm{~m}^{3} /$ ano de madeira em tora, por serraria. As respostas foram obtidas dos proprietários, familiares e funcionários, já que eles vivem na floresta e conhecem todos os detalhes da atividade. A pesquisa foi realizada nos rios Mutuacá, Ajudante e Mazagão, áreas de maior concentração de serrarias no município (Figura 2).

Nesta pesquisa, questionou-se desde as espécies de madeira serrada, cuidados com a regeneração natural, critério utilizado para localização das árvores a serem derrubadas, tipo de equipamento utilizado, métodos de derrubada, transporte e beneficiamento empregados, até os preços praticados e formas de comercialização utilizadas, sendo aplicados os seguintes questionários: 
1. Questões relacionadas às espécies exploradas;

2. Questões relacionadas à compra das árvores;

3. Questões relacionadas à derrubada das árvores;

4. Questões relacionadas ao transporte das toras;

5. Questões relacionadas aos equipamentos existentes na serraria;

6. Questões relacionadas ao beneficiamento das toras na serraria;

7. Questões relacionadas ao beneficiamento e venda das peças;

8. Questões relacionadas à legalização da atividade.

Nos pontos de venda de madeira beneficiada de Macapá e de Santana, aplicou-se questionário apenas para consolidação das respostas aos questionários aplicados aos donos das serrarias.

A madeira explorada e processada nos rios Mazagão, Ajudante e Mutuacá, área de realização do estudo, é vendida pelos estancieiros aos proprietários dos pontos de venda de Macapá e de Santana, razão pela qual aplicou-se questionário apenas a pessoas desses dois locais.

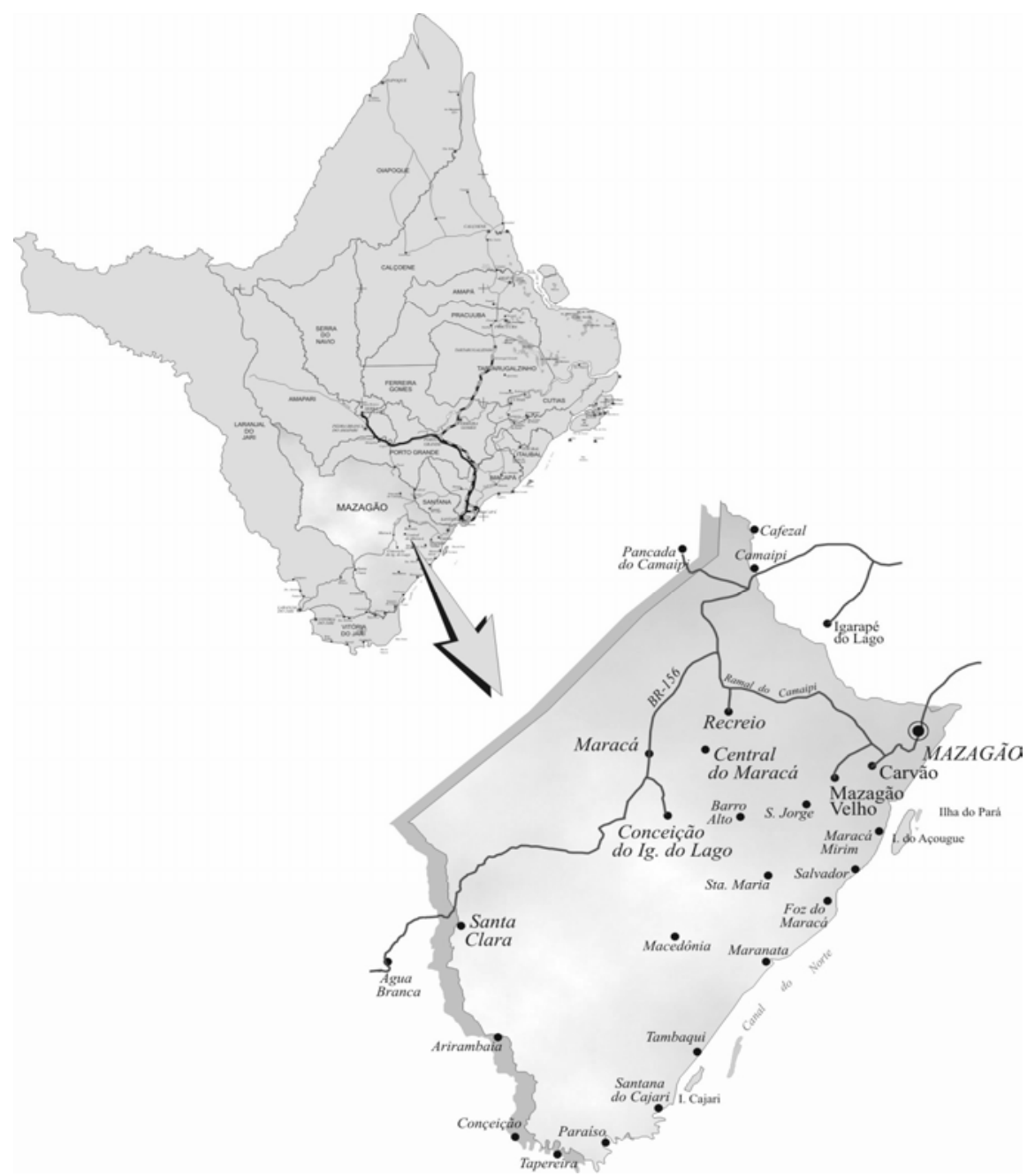

Figura 2. Município de Mazagão, no estado do Amapá (Fonte: ZEE/AP, 2005).

Figure 2. District of Mazagão in Amapá State (Source: ZEE/AP, 2005).

Para a avaliação do estoque de madeira, foram consideradas cinco parcelas de um hectare cada uma, sendo cada parcela subdividida em dez parcelas de 20 × $50 \mathrm{~m}$. No levantamento, foram medidas todas as árvores com CAP (Circunferência à Altura do Peito) maior ou igual a $15 \mathrm{~cm}$, a qual foi 
mensurada com auxílio de fita métrica. As alturas foram obtidas por estimativa, com auxílio de uma régua de 5,0 m, graduada de 1,0 em 1,0 m. No presente trabalho, foram utilizadas as árvores com DAP superior a $10 \mathrm{~cm}$

Para a realização dos estudos fitossociológicos, registrou-se o nome vulgar das espécies e o perímetro medido a $1,30 \mathrm{~m}$ de altura. A identificação foi feita por parataxônomos com experiência no ambiente de várzea estuarina, e as espécies sobre as quais se tinham dúvidas foram levadas para o Herbário do Instituto de Pesquisas Científicas e Tecnológicas do Estado do Amapá-IEPA, para comparação com exsicatas dos referidos materiais.

As parcelas foram instaladas nos seguintes locais: Furo do Mazagão (área do Sr. João Bina), Rio Mutuacá (área do Sr. Veríssimo), Rio Ajudante (área do Sr. Juraci de Almeida), Igarapé Inveja (área do Sr. Wilsinho do Fórum) e Rio Espinhel (área da Sra. Rosário).

\section{RESULTADOS E DISCUSSÃO}

A localização das árvores a serem exploradas acontece no dia-a-dia dos membros da família, ao caminharem na floresta. É dada preferência a árvores que proporcionem mais de três toras de $3 \mathrm{~m}$ cada uma. Raramente são exploradas árvores que proporcionem apenas uma tora de $3 \mathrm{~m}$, que apresentem deformidades ou que estejam ocas. Após a localização da árvore e da decisão de que ela será explorada, é feita uma roçagem em seu entorno, sendo os cipós, caso ainda existentes, eliminados.

Após a derrubada da árvore e o traçamento do fuste, as toras são conduzidas flutuando sobre as águas dos igarapés ou em jangadas montadas com buritizeiros (Mauritia flexuosa L.) ou aningas (Montrichardia arborescens (L.) Schott) e atracadas ao lado de embarcações, sendo os troncos de buritizeiro reutilizados. Quando a árvore derrubada fica distante do igarapé, as toras são conduzidas sobre estivas feitas com as espécies de menor porte, consideradas sem valor comercial. Na montagem da estiva, pedaços de $1 \mathrm{~m}$ de troncos de 10 a $20 \mathrm{~cm}$ de diâmetro são dispostos sobre o solo, com espaço de 1,5 a $2 \mathrm{~m}$ entre eles.

A preferência dos estanceiros por andiroba (Carapa guianensis Aubl.), virola (Virola surinamensis Warb.) e anani (Symphonia globulifera L.) decorre da capacidade que essas espécies têm de flutuar e da preferência do consumidor pela madeira. O elevado estoque de pracuúba (Mora paraensis Ducke) existente nas florestas de várzea do município de Mazagão resulta do fato de a espécie não flutuar, o que dificulta seu transporte, e de sua tendência ao rachamento, o que limita seu uso na produção de esteios, dormentes e pernamancas. Pelo fato de não flutuar, as toras de pracuúba quase sempre são conduzidas em jangadas associadas a outras espécies que flutuam.

Em relação ao número de toras da árvore a ser explorada, não há consenso. Algumas famílias cortam árvores que produzam até uma tora de $4 \mathrm{~m}$, outras famílias só a partir de um rendimento de três toras por árvore. A circunferência mínima de corte mencionada foi $100 \mathrm{~cm}(\mathrm{DAP}=32 \mathrm{~cm})$, havendo quem mencionasse uma CAP mínima de $150 \mathrm{~cm}(\mathrm{DAP}=48 \mathrm{~cm})$. Quando a árvore é comprada em pé, para ser extraída na área de terceiros, só são compradas e extraídas árvores que proporcionem um mínimo de três toras de $3 \mathrm{~m}$ cada uma.

Em estudos realizados na região de várzea do estado do Amapá, Veríssimo et al. (1999) observaram que a capacidade produtiva das serrarias de várzea era extremamente reduzida e que elas utilizavam serras circulares de 40 a 50 polegadas para o processamento da madeira. Por causa da restrição no tamanho da serra, apenas as toras com diâmetro entre 20 e $45 \mathrm{~cm}$ eram aproveitadas.

Os resultados encontrados no presente estudo indicam ter havido um aumento no limite superior do diâmetro das toras processadas nas serrarias do município de Mazagão, no estado do Amapá, o que deve ter contribuído para o aumento na produção.

Não se pode chamar de manejo florestal aos procedimentos de extração empregados. Anualmente são extraídas da área todas as espécies comercializáveis com diâmetro que permita a produção de tábuas e pernamancas $( \pm 30 \mathrm{~cm})$, que se encontram nas proximidades da serraria e o mais próximo possível do igarapé através do qual as toras irão flutuar até a serraria. A distância máxima mencionada, entre o ponto de corte e o igarapé, foi $300 \mathrm{~m}$, sendo mais freqüente a distância máxima de $200 \mathrm{~m}$.

O que contribui para assegurar a manutenção das espécies exploradas na área é o cuidado que os membros das famílias têm para com as mudas e árvores jovens das espécies consideradas de valor comercial, além da excelente capacidade de reposição que essas espécies apresentam. A excelente capacidade de produção de frutos e sementes das espécies exploradas e o vigor das mudas resultantes, como é o caso da pracuúba (Mora paraensis), da andiroba (Carapa guianensis), da macacaúba (Platymiscium filipes Benth.), da virola (Virola surinamensis) e do anani (Symphonia globulifera), por 
exemplo, contribuem para a rápida reposição das espécies. Além disso, a elevada fertilidade dos solos de várzea ajudam no desenvolvimento das árvores.

A árvore é extraída da própria área ou de área de terceiros. Quando extraída da área de terceiros, ela é comprada por preços que variam de $\mathrm{R} \$ 8,00$ a $\mathrm{R} \$ 20,00$ a árvore em pé. Ao serrador é paga uma diária de $\mathrm{R} \$ 13,00$ caso ele seja solteiro e de $\mathrm{R} \$ 15,00$ caso ele seja casado, com o fornecimento de refeição (almoço e lanche). O rendimento varia de três a quatro árvores ( 10 a 15 toras) por homem/dia.

Observou-se grande heterogeneidade no uso de equipamentos de beneficiamento de toras, com utilização de motores com potência variando de $14 \mathrm{HP}$ até $125 \mathrm{HP}$. Os motores, quase todos, foram comprados já usados, e as serras também. Assim, não existe relação direta entre a potência do motor e a bitola dos demais equipamentos e nem com a produção da serraria. Ou seja, uma serraria que use um motor de $50 \mathrm{HP}$ pode produzir mais do que uma serraria que use um motor de $100 \mathrm{HP}$.

$\mathrm{O}$ preço mencionado para a aquisição de motosseras variou de $\mathrm{R} \$ 2.600,00$ a $\mathrm{R} \$ 3.000,00$ dependendo da bitola da serra e do local onde havia sido comprada. O tempo de duração mencionado variou de um ano até sete anos, o qual deve ter tido relação direta com a intensidade de uso e as práticas de manutenção dispensadas ao equipamento. O preço mencionado para a corrente da motossera variou de $\mathrm{R} \$ 63,00$ a $\mathrm{R} \$ 170,00$, e o tempo de duração mencionado variou de 45 dias até seis meses.

Os consumidores demonstram preferência pelas espécies Carapa guianensis Aubl. (andiroba), Virola surinamensis Warb. (virola), Platymiscium filipes Benth. (macacaúba), Mora paraensis Ducke (pracuúba), Callycophyllum spruceanum Benth. (pau-mulato) e Symphonia globulifera L. (anani). Em razão da preferência pela espécie Carapa guianensis, outras árvores são exploradas para serem comercializadas em seu lugar, entre as quais podemos citar: anani (Symphonia globulifera L.), tamaquaré (Caraipa grandiflora Mart.), jacareúba (Calophyllum brasiliensis Cambess), uxirana (Saccoglottis guianensis Aubl.), pracaxi (Pentaclethra macroloba (Willd.) O. Kuntze) e ventosa (Hernandia guianensis Aubl.). A ventosa é uma espécie que proporciona madeira branca macia, usada na divisão de cômodos e forros e na montagem das jangadas utilizadas para ajudar na flutuação do pau-mulato, da pracuúba e da macacaúba.

Em relação às espécies madeireiras exploradas nas áreas de várzea do estuário amazônico, resultados semelhantes foram encontrados por Veríssimo et al. (1999) e Itto (1999), em estudos realizados no estado do Amapá.

De acordo com os proprietários das lojas de venda de madeira que foram entrevistados, as principais utilizações das espécies madeireiras de várzea são:

- Construção de casas: andiroba, pracuúba, pau-mulato.

- Estrutura para telhado: pracuúba.

- Forro: andiroba, pau-mulato, branco da macacaúba.

- Caixa para concreto: virola e madeira de segunda de andiroba e pau-mulato.

- Cercas: madeira de segunda de andiroba, pau-mulato, pracuúba e anani.

- Móveis e esquadrias: macacaúba e cedro.

\section{Produção de madeira - Custo}

De acordo com os proprietários das serrarias, em média são cortadas 7 a 8 toras por dia $\left(3,5 \mathrm{~m}^{3}\right)$, o equivalente a duas árvores. Como pode ser observado na tabela 1, na média para as dez entrevistas efetuadas, constatou-se que o custo das duas árvores em pé ficou em $\mathrm{R} \$ 42,00$. O custo de derrubada das árvores, mais o seu traçamento em toras e acrescentando-se o valor do óleo, ficou em $\mathrm{R} \$ 29,83$ (24,55 + 5,28 de óleo). O transporte das toras até a serraria ficou em $\mathrm{R} \$ 45,00$. O custo do processamento diário destas 7 a 8 toras ficou em 25,00, devendo ser acrescentado o custo do óleo, o qual é obtido mediante a troca com os resíduos gerados pela serraria, numa relação de 20 metros de lenha por 30 litros de óleo. Atribuiu-se ainda um custo médio de manutenção de R \$20,00. Somando-se todos os itens, chega-se a um custo operacional diário em torno de $\mathrm{R} \$ 200,00$.

Observa-se ainda na tabela 1, que a produção diária de tábuas, pernamancas, ripas e ripões foi de 20 dúzias em média. Para as ripas e ripões, cada duas dúzias equivale a uma dúzia de tábua ou pernamanca. Considerando o preço médio de venda de $\mathrm{R} \$ 18,00$ a dúzia, as 7 a 8 toras processadas diariamente proporcionam uma arrecadação que se aproxima dos $\mathrm{R} \$ 360,00$. Somando-se todas as despesas, tem-se que o custo operacional relatado pelos proprietários das serrarias foi inferior a R\$ 200,00. Considerando que as instalações (ativos) são edificadas com madeiras retiradas na própria área e os equipamentos (ativos) são adquiridos de terceiros ou de sucatas, na maioria dos casos, o retorno ainda é satisfatório, quando comparado aos resultados obtidos com a implantação de roçados, por exemplo. 
Convém registrar que não existe regularidade no funcionamento das serrarias. A pane num equipamento, por exemplo, é problema de difícil solução, que pode levar a vários dias de paralisação das atividades. A doença de um operador de máquina também pode levar a paralisações demoradas, em razão das dificuldades que se tem para conseguir um substituto. É raro uma serraria que funcione mais de 200 dias no ano.

A exploração das árvores e o traçamento das toras são realizados, principalmente, no período seco, principalmente nos meses de outubro, novembro e dezembro. O transporte é feito no período chuvoso, pois os rios e igarapés ficam transbordando de água, facilitando a condução das toras até a serraria. O beneficiamento das toras, transformando-as em tábuas, pernamancas, ripas e ripões é feito durante o ano inteiro.

A troca dos restos de madeira por óleo diesel pode até ser considerado um mau uso da madeira, já que ela será queimada para gerar energia para a empresa que a adquiriu. Entretanto, convém considerar que tal iniciativa evita o desperdício e, no momento atual, contribui de forma positiva para o sucesso financeiro do empreendimento.

Tabela 1. Custo de produção (R\$) para 7 a 8 toras/dia (3,5 $\mathrm{m}^{3}$ de madeira), Mazagão (AP).

Table 1. Cost of production (R\$) for 7 to $8 \operatorname{logs} /$ day $\left(3,5 \mathrm{~m}^{3}\right.$ of wood), Mazagão (AP).

\begin{tabular}{|c|c|c|c|c|c|c|c|c|}
\hline \multirow{2}{*}{$\begin{array}{l}\text { Unidade de } \\
\text { amostra }\end{array}$} & \multirow{2}{*}{$\begin{array}{l}\text { Árvore } \\
\text { em pé }\end{array}$} & \multirow{2}{*}{$\begin{array}{l}\text { Derrubada e } \\
\text { corte em toras }\end{array}$} & \multicolumn{2}{|c|}{ Transporte (até) } & \multirow{2}{*}{$\begin{array}{l}\text { Processamento } \\
\text { Diária + óleo*** }\end{array}$} & \multirow[t]{2}{*}{ Man. } & \multirow{2}{*}{$\begin{array}{c}\text { Produtos } \\
\text { obtidos (dz) }\end{array}$} & \multirow{2}{*}{$\begin{array}{c}\text { RS } \\
\text { Arrec. }\end{array}$} \\
\hline & & & Igarapé & Serraria & & & & \\
\hline 01 & 30,00 & $15,00+5,50$ & 30,00 & NI & $20,00+40,00$ & & 25 & 450,00 \\
\hline 02 & 60,00 & $20,00+5,50$ & 20,00 & 30,00 & $30,00+40,00$ & & 28 & 504,00 \\
\hline 03 & 60,00 & $30,00+3,50$ & NI & NI & $20,00+30,00$ & & 25 & 450,00 \\
\hline 04 & 60,00 & $30,00+8,00$ & NI & NI & $20,00+40,00$ & & 24 & 432,00 \\
\hline 05 & 30,00 & $20,00+8,00$ & NI & NI & $20,00+30,00$ & & 20 & 360,00 \\
\hline 06 & $30,00 *$ & 20,00 & 15,00 & 15,00 & $30,00+\mathrm{NI}$ & & 18 & 324,00 \\
\hline 07 & $30,00^{*}$ & $20,00+5,50$ & NI & NI & $20,00+30,00$ & & 18 & 324,00 \\
\hline 08 & 30,00 & Família & NI & NI & $30,00+10,00$ & & 15 & 270,00 \\
\hline 09 & $30,00^{*}$ & $40,00+3,50$ & NI & 25,00 & $30,00+10,00$ & & 12 & 216,00 \\
\hline 10 & 60,00 & $26,00+2,75$ & NI & NI & $30,00+15,00$ & & 15 & 270,00 \\
\hline Média & 42,00 & $24,55+5,28 *$ & 21,67 & 23,33 & 25,00 & 20,00 & 20 & 360,00 \\
\hline
\end{tabular}

*Da propriedade; **óleo obtido pela troca com lenha; NI: Não informou; Man.: Manutenção; Arrec.: Arrecadado. Produtos obtidos: tábuas, pernamancas, ripas e ripões em dúzia (dz) na serraria.

Atualmente, em média são produzidas, por ano, 3.000 dúzias de tábuas e pernamancas (20 dúzias x 150 dias). Considerando que para a produção de 20 dúzias são necessárias duas árvores, essa produção demandaria a derrubada de pouco mais de 300 árvores por ano. Para um estancieiro com área de 200 ha, que é o tamanho mais comum das propriedades, seria necessária a retirada de 1,5 árvores/ha/dia.

De acordo com os proprietários das serrarias, se tudo funcionar bem e com um pequeno apoio dado pelo Governo, a produção média anual poderia chegar a 10.000 dúzias, entre tábuas, pernamancas, ripas e ripões. Considerando que para a produção de 20 dúzias são necessárias duas árvores, esta produção demandaria pouco mais de 1000 árvores por ano, com derrubada de 5 árvores/ha.

A ajuda do Governo seria principalmente com a regularização fundiária, o que permitiria a legalização do empreendimento, a elaboração e aplicação de planos de manejo, o acesso ao crédito e a comercialização da produção mais favorável aos donos das serrarias, pelo fato de não atuarem na clandestinidade.

O levantamento fitossociológico, considerando as árvores com DAP $\geq 10 \mathrm{~cm}$, apresentou como resultado, para as cinco parcelas de estudo, 93 espécies incluídas em 32 famílias botânicas, para um total de 733,8 árvores por hectare.

Como pode ser observado na tabela 2 , para as espécies atualmente comercializadas, entre as classes de 10 a $20 \mathrm{~cm}$ de DAP, foram encontradas 71,2 árvores/ha; entre 20 a $40 \mathrm{~cm}, 71,8$ árvores/ha; e com DAP superior a $40 \mathrm{~cm}, 28,2$ árvores/ha. O número de árvores das espécies exploradas, com DAP em dimensões adequadas ao corte, é suficiente para atender a demanda das serrarias no nível de produção atual, que é de 300 árvores, e o número de árvores com DAP entre 20 e $40 \mathrm{~cm}$ é bastante elevado, com excelentes possibilidades de manutenção das demandas futuras, mesmo que haja aumentos nos volumes explorados futuramente. 
Tabela 2. Árvores comercializadas, utilizadas e potenciais nas cinco parcelas de estudo, para as três classes de DAP por espécie, Mazagão (AP).

Table 2. Trees commercialized, utilised and potential in the five sampled plots for the three classes of DAP by species, Mazagão (AP).

\begin{tabular}{|c|c|c|c|c|c|}
\hline \multirow{2}{*}{ Nome comum } & \multirow{2}{*}{ Nome científico } & \multirow{2}{*}{ Família } & \multicolumn{3}{|c|}{ DAP (cm) } \\
\hline & & & 10 a 20 & 20 a 40 & $>40$ \\
\hline \multicolumn{6}{|c|}{ Espécies comercializadas } \\
\hline Andiroba & Carapa guianensis Aubl. & Meliaceae & 47 & 62 & 12 \\
\hline Pau-mulato & Callycophyllum spruceanum Benth. & Rubiaceae & - & 11 & 22 \\
\hline Macacaúba & Platymiscium filipes Benth. & Fabaceae & 3 & 7 & 3 \\
\hline Pracuúba & Mora paraensis Ducke & Caesalpiniaceae & 142 & 118 & 74 \\
\hline Virola & Virola surinamensis Warb. & Myristicaceae & 26 & 33 & 10 \\
\hline Anani & Symphonia globulifera L. & Clusiaceae & 8 & 7 & 3 \\
\hline Pracaxi & Pentaclethra macroloba O. Kuntze & Mimosaceae & 121 & 118 & 16 \\
\hline Tamaquaré & Caraipa grandiflora Mart. & Clusiaceae & 2 & - & - \\
\hline Jacareúba & Calophyllum brasiliensis Cambess. & Clusiaceae & 1 & 1 & - \\
\hline Uxirana & Saccoglottis guianensis Aubl. & Humiriaceae & 4 & - & - \\
\hline Ventosa & Hernandia guianensis Aubl. & Hernandiaceae & 2 & 2 & 1 \\
\hline Total & & & 356 & 359 & 141 \\
\hline Média/ha & & & 71,2 & 71,8 & 28,2 \\
\hline \multicolumn{6}{|c|}{ Espécies utilizadas } \\
\hline Maúba & Licaria mahuba Kosterm & Lauraceae & 9 & 6 & 1 \\
\hline Abiurana & Pouteria biloculares Baehni & Sapotaceae & 1 & 9 & 7 \\
\hline Assacu & Hura crepitans Muell. Arg. & Euphorbiaceae & 3 & 1 & 5 \\
\hline Ceru & Allantoma lineata Miers & Lecythidaceae & 1 & 5 & 4 \\
\hline Taperebá & Spondias mombin L. & Anacardiaceae & 5 & 2 & 4 \\
\hline Acariquara & Minquartia guianensis Aubl. & Olacaceae & 1 & - & - \\
\hline Muiratinga & Olmedia caloneura Huber & Moraceae & 1 & 7 & 5 \\
\hline Jutaí-Folha-Fina & Himenaea oblongifolia Huber & Caesalpiniaceae & 4 & 3 & - \\
\hline Jutaí-Folha-Larga & Macrolobium augustifolium R.S.Cowan & Caesalpiniaceae & 12 & 11 & 3 \\
\hline Faveira & Vatairea guianensis Aubl. & Fabaceae & 2 & 2 & 9 \\
\hline Cedro & Cedrela odorata $\mathrm{L}$. & Meliaceae & 2 & 1 & - \\
\hline Arapari & Macrolobium acaciaefolium Benth. & Caesalpiniaceae & 1 & - & 6 \\
\hline Maçaranduba & Pouteria sagotiana Eyma & Sapotaceae & 5 & 5 & 1 \\
\hline Mamorana & Bombax sp & Bombaceae & - & - & 3 \\
\hline Paranari & Parinarium excelsa Sabine & Chrysobalanaceae & - & - & 1 \\
\hline Pau-de-arara & Aspidosperma desmanthum Benth. & Apocynaceae & 2 & 6 & 4 \\
\hline Total & & & 49 & 58 & 53 \\
\hline Média/ha & & & 9,8 & 11,6 & 10,6 \\
\hline \multicolumn{6}{|c|}{ Espécies potenciais } \\
\hline Chapéu-de-sol & Apeiba burchelli Sprague & Tiliaceae & 1 & 2 & 1 \\
\hline Cinzeiro & Terminalia guianensis Aubl. & Combretaceae & 4 & 3 & 11 \\
\hline Cumarurana & Dipteryx $\mathrm{sp}$ & Fabaceae & 2 & 11 & 2 \\
\hline Anoerá & Licania macrophylla Benth. & Chrysobalanaceae & 18 & 20 & 5 \\
\hline Macucu & Licania heteromorpha Benth. & Chrysobalanaceae & 12 & 10 & 8 \\
\hline Mututi & Pterocarpus amazonicus Huber & Fabaceae & 19 & 19 & 9 \\
\hline Pacapeuá & Swartzia cardiosperma Spr. ex Benth. & Caesalpiniaceae & 31 & 28 & 7 \\
\hline Total & & & 87 & 93 & 43 \\
\hline Média/ha & & & 17,4 & 18,6 & 8,6 \\
\hline Total geral & & & 492 & 510 & 237 \\
\hline Média geral/ha & & & 98,4 & 102 & 47,4 \\
\hline
\end{tabular}

Espécies comercializadas: espécies madeireiras exploradas, processadas e comercializdas atualmente.

Espécies utilizadas: espécies madeireiras utilizadas pelos ribeirinhos, na construção de casas, pocilgas etc.

Espécies potenciais: espécies madeireiras não utilizadas. 
Mesmo com a exclusão das espécies pracaxi e ventosa, em razão do baixo valor obtido pela madeira, a média de árvores comercializadas com DAP $\geq 40 \mathrm{~cm}$ ficaria em 24,8/ha, bem acima do explorado atualmente.

Em estudos realizados em área de propriedade da madeireira EMAPA, no município de Afuá (PA), para conhecimento da composição florística, análise da estrutura e valoração de uma floresta de várzea alta não explorada, Bentes-Gama; Scolforo; Gama; e Oliveira (2002) citam, como espécies que se destacaram pelo IVI (Índice de Valor de Importância) obtido, Eschweilera coriacea S. A. Mori, Swartzia racemosa Benth., Virola surinamensis Warb., Licania Macrophylla Klotzsch e Ingá edulis Mart., sendo que as espécies Virola surinamensis e Eschweilera coriacea apresentaram o maior número de toras comercializáveis, com 25 toras/ha e 17 toras/ha, respectivamente, quando consideradas apenas as árvores com DAP $\geq 45 \mathrm{~cm}$.

Os resultados encontrados no presente estudo diferem bastante dos resultados encontrados por Bentes-Gama; Scolforo; Gama; e Oliveira (2002), em Afuá (PA). As diferenças são muito mais evidentes com relação às espécies do que com relação aos volumes encontrados. É provável que explorações realizadas em anos anteriores na área de Mazagão (AP) tenham reduzido drasticamente a densidade de Eschweilera coriacea e Swartzia racemosa, espécies de alto IVI na área de Afuá (PA). Também chama a atenção o reduzido valor de importância obtido pelas espécies Mora paraensis e Pentaclethra macroloba na área de Afuá (PA), espécies que obtiveram elevado IVI na área de Mazagão (AP).

\section{CONCLUSÕES}

Dentre as espécies madeireiras de várzea, as preferidas pelos moradores de Macapá e de Santana, os dois maiores municípios do estado do Amapá, para atendimento das demandas de construção de casas, fabricação de móveis, instalação de cercados, etc., são: Carapa guianensis (andiroba), Virola surinamensis (virola), Callycophyllum spruceanum (pau-mulato), Platymiscium filipes (macacaúba), Mora paraensis (pracuúba) e Symphonia globulifera (anani).

A densidade das espécies madeiráveis, com diâmetro em ponto de corte, atualmente existente nas propriedades dos donos de serrarias em funcionamento na área de estudo, é suficiente para manter a produção atual de madeira serrada, pelo menos, por 20 anos. Após esse período, o estoque remanescente poderá proporcionar o dobro do volume atualmente existente.

A diversidade e a integridade da floresta, na área de estudo, mostram que mesmo sem seguir planos técnicos de manejo adequadamente elaborados, os impactos da atividade florestal ao ambiente são baixos, os quais poderiam ser ainda menores, se os ribeirinhos recebessem orientação técnica adequada e dispusessem de meios para o aproveitamento de um número maior de espécies, o que reduziria a seletividade.

A exploração madeireira no nível familiar é economicamente viável, com geração de ocupação e renda para os extrativistas da região, sendo aconselhável sua manutenção.

\section{REFERÊNCIAS}

BENTES-GAMA, M. de M.; SCOLFORO, J. R. S.; GAMA, J. R. V.; OLIVEIRA, A. D. Estrutura e valoração de uma floresta de várzea alta na Amazônia. Cerne, Lavras, v. 8, n. 1, p. 88-102, 2002.

DUCKE, A.; BLACK, G. A. Notas sobre a fitogeografia da Amazônia Brasileira. Belém: Instituto Agronômico do Norte, 1954. 62 p. (Boletim Técnico, 29)

INSTITUTO DE PESQUISAS CIENTÍFICAS E TECNOLÓGICAS DO ESTADO DO AMAPÁ. Macrodiagnóstico do Estado do Amapá: primeira aproximação do ZEE. Macapá, 2002, 140 p.

INSTITUTO DE PESQUISAS CIENTÍFICAS E TECNOLÓGICAS DO ESTADO DO AMAPÁ. Zoneamento Ecológico Econômico da Área Sul do Estado do Amapá - ATLAS. Macapá, 2000.

INTERNATIONAL TROPICAL TIMBER ORGANIZATION. Curso de disseminação e treinamento nas diretrizes e critérios da ITTO: Fase II, Estágio 2. Macapá, 1999. 
LIMA, R. R.; TOURINHO, M. M. Várzeas da Amazônia Brasileira: principais características e possibilidades agropecuárias. Belém: FCAP. Serviço de Documentação e Informação, 1994. 20 p.

QUEIROZ, J. A. L. de Fitossociologia e distribuição diamétrica em floresta de várzea do estuário do Rio Amazonas no Estado do Amapá. 101 f. Dissertação (Mestrado em Ciências Florestais) - Setor de Ciências Agrárias, Universidade Federal do Paraná, Curitiba, 2004.

QUEIROZ, J. A. L. de; MOCHIUTTI, S. Efeito do manejo de açaizais sobre a diversidade de espécies florestais no Estuário Amazônico. In: SIMPÓSIO INTERNACIONAL DA IUFRO, Belém, 2000, Resumos... [S.1.], 2000. p. 135.

RABELO, B. V. (Coord.). Mazagão: realidades que devem ser conhecidas. Macapá: Instituto de Pesquisas Científicas e Tecnológicas do Estado do Amapá, 2005. 119 p.

VERÍSSIMO, A.; CAVALCANTE, A.; VIDAL, E.; LIMA, E.; PANTOJA, F.; BRITO, M. O setor madeireiro no Amapá: situação atual e perspectivas para o desenvolvimento sustentável. Belém: IMAZON, 1999. 